\title{
Effects of Static and Dynamic Stretching Exercises on Unilateral Hamstring to Quadriceps Strength Ratio
}

\author{
Nikolina Gerdijan1, Dušan Perić ${ }^{*}$, Adriana Ljubojević1 ${ }^{1}$ Željko Vukić1 \\ ${ }^{1}$ Faculty of Physical Education and Sports, University of Banja Luka, Banja Luka, Bosnia and Herzegovina \\ ${ }^{2}$ Faculty of sport and tourism, Educons University, Novi Sad, Serbia \\ Email: *dusan.peric@tims.edu.rs
}

How to cite this paper: Gerdijan, N., Perić, D., Ljubojević, A., \& Vukić, Ž. (2021). Effects of Static and Dynamic Stretching Exercises on Unilateral Hamstring to Quadriceps Strength Ratio. Advances in Physical Education, 11, 89-102.

https://doi.org/10.4236/ape.2021.111007

Received: January 5, 2021

Accepted: February 22, 2021

Published: February 25, 2021

Copyright $\odot 2021$ by author(s) and Scientific Research Publishing Inc. This work is licensed under the Creative Commons Attribution International License (CC BY 4.0).

http://creativecommons.org/licenses/by/4.0/

\begin{abstract}
Traditional warm-up in sport contents the stretching. The stretching effects are a frequent subject of research in physical education, but the results are conflicting. The aim of current study is to check how acute stretching (static and dynamic) influences to the strength of hamstring and quadriceps, as well as their mutual ratio. These variables were monitored at different velocities of contraction (60 and $240 \%$ s). On the sample of 10 students in good health, modern isokinetic diagnostics $(4000 \mathrm{~Hz}$ the sampling rate) was applied. Higher strength values in both muscle groups were measured during slow contraction, while HRQ values were higher during fast contractions. The results show that the muscle strength of hamstring and quadriceps can be increased by applying acute stretching $(p<0.05)$, but at the same time the HQR does not change significantly $(p>0.05)$. The same conclusions were drawn for both low and high contraction velocities.
\end{abstract}

\section{Keywords}

Isokinetic Test, Muscle Imbalance, Knee Extensors, Knee Flexors, Contraction Velocity

\section{Introduction}

Many athletes perform pre-exercise stretching as an integral part of their warm-up activities, as to maximize the sport performance and prepare the body for training sessions or competition. The stretching effects are a frequent subject of research in sports and physical education. Despite numerous empirical studies, 
there are still some dilemmas about stretching. Results from different researches are often conflicting. Variations in methodology and testing protocols compromise the comparison between published data in literature.

The stretching portion traditionally incorporated static stretching. Static stretching usually involves moving a limb to the end of its range of motion and holding the stretched position for 15-16 seconds (Young, 2007; Young \& Behm, 2002). Although there is strong evidence regarding the deleterious effects of static stretching and benefits of dynamic stretching prior to performance, there are some studies reporting of no impairments or facilitations.

Some experts state that static stretching immediately before a competition positively affects the performance and the functional abilities of the athletes (Power, Behm, Cahill, Carroll, \& Young, 2004). Static stretching may pro-vide benefits in some cases such as slower velocity eccentric contractions, and contractions of more prolonged duration or stretch-shortening cycle (Behm \& Chaouachi, 2011). At the same time, there are many studies indicated a negative influence of static stretching on the explosive strength (Brandenburg, 2006; Knudson, Bennett, Corn, Leick, \& Smith, 2001; Taylor, Sheppard, Lee, \& Plummer, 2009; Unick, Kieffer, Cheesman, \& Feeney, 2005; Young \& Behm, 2003).

In addition, static stretching used in a separate training session can provide health related range of motion benefits. The proposed benefits of static stretching were the reduction or prevention of injury, a decrease in subsequent muscle soreness and improved performance (Young \& Behm, 2002; Young, 2007). The improvement in performance has been suggested to be due to the enhanced ability to stretch or reach during a sport as well as the decreased resistance of a more compliant or less stiff muscle to the intended movement (Young, 2007). However, some researchers have concluded that stretching has no effect on injury prevention (Herbert \& Gabriel, 2002; Pope, Herbert, Kirwan, \& Graham, 2000; Small, Mc Naughton, \& Matthews, 2008).

Dynamic stretching that involves controlled movement through the active range of motion for a joint (Fletcher, 2010) show either facilitation of power (Manoel, Harris-Love, Danoff, \& Miller, 2008; Yamaguchi et al., 2008), sprint (Fletcher \& Anness, 2007; Little \& Williams, 2006) and jump (Holt \& Lambourne, 2008; Hough, Ross, \& Howatson, 2009; Jaggers, Swank, Frost, \& Lee, 2008; Pearce, Kidgell, Zois, \& Carlson, 2009) performance or no adverse effect (Christensen \& Nordstrom, 2008; Samuel, Holcomb, Guadagnoli, Rubley, \& Wallmann, 2008; Torres et al., 2008; Unick et al., 2005). In the context of dynamic stretching, the literature tends to indicate that shorter durations of dynamic stretching do not adversely affect performance and longer duration of dynamic stretches may facilitate performances (Hough et al., 2009; Pearce et al., 2009; Yamaguchi, Ishii, Yamanaka, \& Yasuda, 2008).

Proper balance of agonist and antagonist muscles is important for joint stabilization during the dynamic movement (Hewett, Myer, \& Zazulak, 2008; Kim \& Hong, 2011; Knapik et al., 2004). To our knowledge, there are no relevant stu- 
dies focused on evaluating the acute effect of stretching on the antagonists muscle strength ratio, specifically on hamstring to quadriceps ratio (HQR). Researchers have consistently proposed that balance of these opposing muscles is imperative in maintaining ideal joint position, therefore it is a critical factor for avoiding injuries during the athletic movements such as jumping, pivoting, and crosscutting (Dontigny, 2005; Solomonow \& Krogsgaard, 2001). One of the most important goals of prophylactic training programs is to enhance neuromuscular balance of hamstring and quadriceps muscles (Hewett, Myer, \& Ford, 2001; Myer, Ford, \& Hewett, 2004). The instability at the knee joint can cause dysfunction at ankle, hip, and eventually upper body joints through the kinetic chain because the person would use compensatory movement strategies in order to avoid pain and injuries (Kim \& Hong, 2011).

The aim of our study was to check by means of isokinetic diagnostics, which is considered to be the most reliable method of measurement, how acute stretching (static and dynamic), performed during warm-up, influence to the unilateral strength of hamstring and quadriceps, as well as their mutual ratio. These variables were monitored at different velocities of contraction. Therefore, the main question that this study was supposed to answer is: can the unilateral Hamstring to Quadriceps strength ratio (HQR) be improved by acute stretching?

\section{Methods}

\subsection{Participants and Study Design}

This research was done as a pilot study with a group composed of 10 healthy young males aged between 20-21 years (students of sports faculty). The group was very homogeneous in terms of anthropometric and motoric characteristics. The participants have been familiarized with the measuring protocol and they signed consent of voluntary accession to the test. The study was performed in accordance with the Declaration of Helsinki and was approved by the Ethics Board of Faculty of physical education and sport. The subjects were informed of the benefits and risks of the investigation prior to signing an institutionally approved informed consent document to participate in the study.

The participants underwent isokinetic testing using a computerized dynamometer. They performed flexion and extension movements at different velocity, first in the form of slow, then fast contraction. The same diagnostic protocol was conducted three times under different circumstances: 1) no stretching before isokinetic test; 2) with dynamic stretching; and 3) with static stretching applied before test. A week long pause was taken between each test, in order to eliminate the effects of fatigue and the excitation of motor units. In the period between the testing, subjects performed their regular daily activities and were not subjected to any systematic training.

\subsection{Variables and Measurement Protocol}

Testing was performed by the same experienced examiner in the Laboratory for 
isokinetic testing at the Faculty of physical education and sport in Banja Luka, Bosnia and Herzegovina. Laboratory was air-conditioned and room temperature was held between $22^{\circ} \mathrm{C}-24^{\circ} \mathrm{C}$. Testing was performed between $10 \mathrm{AM}$ and 2 PM.

Variables was recorded using a Con-Trex type dynamometer (CON-TREX ${ }^{\oplus}$ MJ isokinetic multi joint module) which registered automatically the force variables during the muscle contraction. The sampling rate was $4000 \mathrm{~Hz}$ and ensured very precise control of the dynamometer and reduces unwanted jitter (temporal frequency deviation in the control system). This devise records many force variables, and only three were used in this study: 1) peak torque of knee flexion (Hamstring strength); 2) peak torque of knee extension (Quadriceps strength); and 3) Hamstring to Quadriceps strength ratio (HQR). The torque was expressed as a relative measure $(\mathrm{Nm} / \mathrm{kp})$ to eliminate the interfering influence of body weight. HQR was expressed as percentage value (\%). Peak torque was measured in concentric and eccentric mode at angular velocities of 60 and 240 degree per second $(\%)$. The participants performed 10 maximal efforts. Mean isokinetic peak torque was calculated based on the highest 3 peak torques.

After warming up by running at a moderate pace for 5 minutes (and specific stretching) participants approached the isokinetic apparatus and, during the next two minutes, were positioned properly in relation to the dynamometer. The test consisted of two parts. In the first part the slow contraction movements of flexion-extension at $60 \%$ were applied. These efforts correspond to the maximum power zone, given that these produced the highest value of force. Each subject performed a series of consecutive slow contractions. This was followed by a break of one minute. The second part of the test was carried out immediately after the break and used to apply the same flexion-extension contraction movements, but at a velocity of $240 \%$ s. These efforts correspond to the quick power zone. Each subject performed a series of 10 consecutive contractions. Just dominant leg was measured. All variables were automatically registered by the software of the isokinetic devise.

\subsection{Dynamic and Static Stretching}

The stretching program was carried out immediately before the isokinetic test. After the five minute warm up, the participants were asked to do a stretching program which consisted of 4 exercises ( 2 for stretching the quadriceps and 2 for the hamstring). The stretching exercise for the quadriceps are: 1) standing quad stretch (at standing position on one leg, placing a hand on the wall for balance, the other leg is stretching by maximum knee flexion) and 2) forward lunges (the large step forward with the feet hip hip-width apart; the body is lowering toward the floor; anterior leg is bent at a maximum angle). The stretching exercise for the hamstring are: 1) standing hamstring stretch (at standing position with the feet hip-width apart and stretched knees, the body is bend forward at the hips, lowering the head toward floor; the arms are wrapping around lower legs) and 2) 
raising leg (from the initial standing position a bent leg is raising towards the chest).

The same exercises were used in both stretching protocols (dynamic and static), but in the first protocol muscles were stretched using the dynamic mode (short interval swings), while in the second regime the exercises were performed in static positions after reaching the maximum amplitude. Each individual exercise was repeated four times for the duration of 20 seconds. The pause between repetitions was 10 seconds as well as the pause between exercises. The total duration of the entire protocol of the stretching exercises was 5 minutes. After the exercise, the subjects were given short two-minute break in order to prepare themselves for the upcoming isokinetic test.

\subsection{Statistical Analysis}

For each variable, arithmetic mean (Mean) and standard deviation (SD) were registered. The impact of different stretching regimes at different contraction velocity was tested by two-factor analysis of variance (two-way ANOVA). The interaction and separate influence of each factor (stretching model and contraction velocity) was tested.

The assumption of homogeneity of variances was checked by Levene's Test (Tabachnick \& Fidell, 2013). The actual impact of the independent variables, both common and separate, was assessed using Partial Eta Squared (PES) based on the criteria proposed by Cohen (1988).

Portable IBM SPSS v.21 application was used for complete statistical analysis (License Stats Prem: $761 b 17 d c f d 1 b f 20 d a 576$ by Hearne software). All conclusions were realized with 0.05 level of significance $(p<0.05)$.

\section{Results}

The influence of dynamic and static stretching, at low and high velocity contractions, on the strength and interrelationship of muscles of front and rear thigh lodges (quadriceps and hamstring) was investigated by two-way ANOVA. Levene's Test confirmed that the variances of the different groups were homogeneous for all variables, thus fulfilling the basic assumption to use this statistical procedure (Hamstring: $\mathrm{F}=0.582 ; p=0.713$; Quadriceps: $\mathrm{F}=1.9 ; p=0.11$; $\mathrm{HQR}$ : $\mathrm{F}=2.049 ; p=0.086)$. Descriptive statistics for all variables, obtained in different situations, are shown in Table 1, and the results of the analysis of variance in Table 2.

The influence of factor interaction (contraction velocity and stretching regime) was not statistically significant in any of the variables $(p>0.05)$. The separate effect of contraction velocity was significant in all three variables $(p<$ $0.05)$. Higher strength values in both muscle groups (hamstring and quadriceps) were measured during slow con-tractions (Velocity $=60^{\circ} / \mathrm{s}$ ), while HRQ values were higher during fast contractions (Velocity $=240^{\circ} / \mathrm{s}$ ) as the corresponding 
graphs show (Figure 1). The separate influence of stretching was significant only Table 1. Descriptive statistics obtained for different stretching regimes at different contraction velocity.

\begin{tabular}{cccc}
\hline Contraction velocity & & $60 \%$ s & $240 \%$ \\
\hline Variables & Stretching & Mean \pm SD & Mean \pm SD \\
\hline Hamstring strength $(\mathrm{Nm} / \mathrm{kp})$ & No & $2.25 \pm 0.27$ & $1.51 \pm 0.27$ \\
& Dynamic & $2.41 \pm 0.21$ & $1.86 \pm 0.16$ \\
& Static & $2.42 \pm 0.22$ & $1.71 \pm 0.23$ \\
\hline Quadriceps strength $(\mathrm{Nm} / \mathrm{kp})$ & No & $2.67 \pm 0.22$ & $1.42 \pm 0.18$ \\
& Dynamic & $3.06 \pm 0.32$ & $1.70 \pm 0.14$ \\
& Static & $3.05 \pm 0.26$ & $1.65 \pm 0.15$ \\
\hline Hamstring/Quadriceps Ratio (HQR) & No & $0.84 \pm 0.09$ & $1.07 \pm 0.18$ \\
& Dynamic & $0.79 \pm 0.06$ & $1.09 \pm 0.12$ \\
& Static & $0.79 \pm 0.08$ & $1.04 \pm 0.13$ \\
\hline
\end{tabular}

Mean-Arithmetic mean; SD—Standard deviation.

Table 2. Statistics of Two-way ANOVA for data from Table 1.

\begin{tabular}{ccccc}
\hline Variable & Impact & $F$ & $\boldsymbol{p}$ & Partial Eta Squared \\
\hline \multirow{3}{*}{ Hamstring strength } & Factor interaction & 0.931 & 0.400 & 0.033 \\
& Contraction velocity & 128.257 & $<0.001$ & 0.704 \\
& Stretching regime & 6.589 & 0.003 & 0.196 \\
\hline \multirow{2}{*}{ Quadriceps strength } & Factor interaction & 0.672 & 0.515 & 0.024 \\
& Contraction velocity & 540.934 & $<0.001$ & 0.909 \\
& Stretching regime & 13.927 & $<0.001$ & 0.340 \\
\hline \multirow{3}{*}{ Hamstring/Quadriceps Ratio } & Factor interaction & 0.577 & 0.565 & 0.021 \\
& Contraction velocity & 69,890 & $<0.001$ & 0.564 \\
& Stretching regime & 0.557 & 0.576 & 0.020 \\
\hline
\end{tabular}

in the strength variables, but not in the HQR.

The Post Hoc analysis revealed that the only source of strength variability are significantly lower values measured in a situation where stretching was not applied before the isokinetic test. Tukey HSD showed that the strength level did not differ significantly after dynamic and static stretching in either the hamstring or the quadriceps. At the same time, changes in HQR under the influence of different stretching regimes were not statistically significant at either low or high contraction velocities. These data show that the muscle strength of both thigh lodges can be in-creased by applying acute stretching (both static and dynamic), but at the same time their mutual ratio (HQR) does not change significantly.

\section{Discussion}

The purpose of this study was to compare the acute effects of static and dynamic 
stretching on isokinetic muscle performance in young healthy males and, in
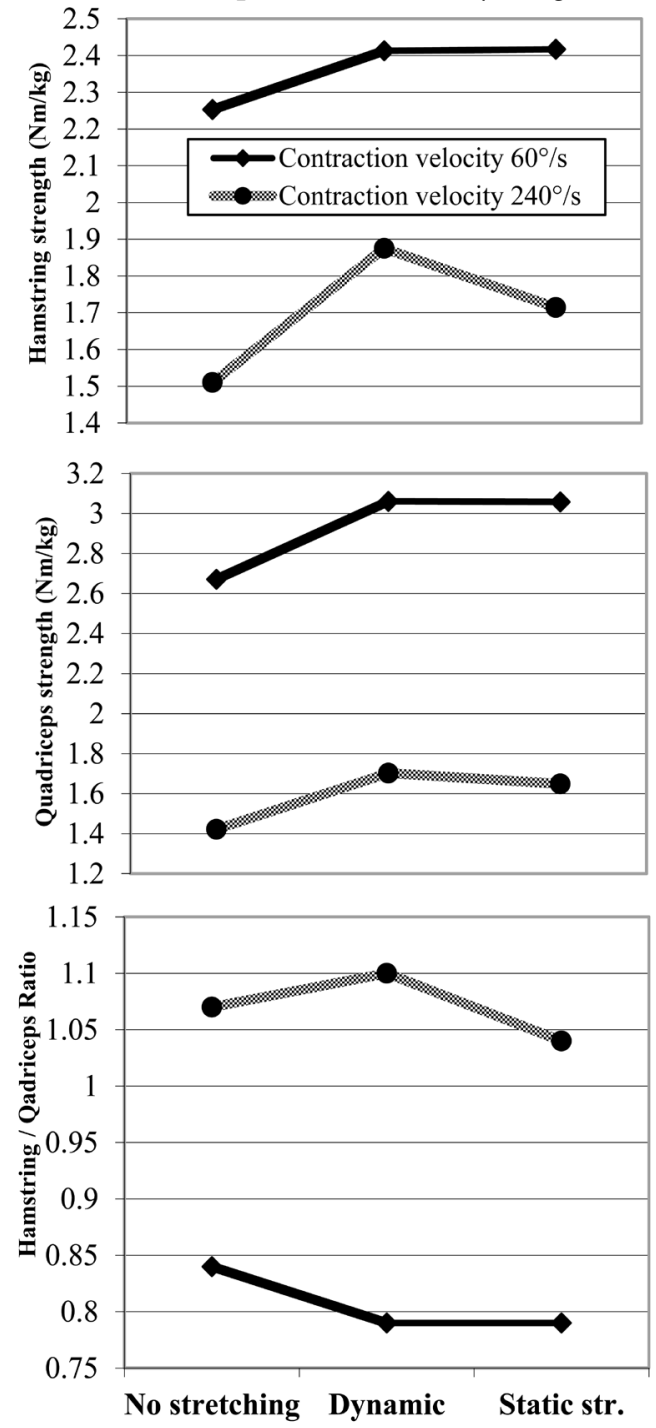

Figure 1. Average values of variables registered for different stretching regime and contraction velocity.

particular, to determine whether any of these techniques would lead to short-term changes in isokinetic power and HQR output of the knee flexors and extensors. The statistical analysis demonstrated that subjects were able to use these stretching techniques without a decrease in absolute levels of knee flexors and extensor power. When changes in power output were analyzed, the static and dynamic stretching techniques resulted in a positive change for both muscle groups (by power increasing of hamstring and quadriceps). This was true for both contraction velocities $\left(60^{\circ} / \mathrm{s}\right.$ and $\left.240 \% \mathrm{~s}\right)$. At the same time, the significant changes for the HQR were no found. The data obtained show that acute stretching cannot affect the improvement of the muscle balance between the hamstring and the quadriceps. Optimal HQR, obviously, can only be achieved by prior long-term systematic treatment of these muscle groups. 
Apart from current separate strength of the hamstring and quadriceps, previous studies have shown that for the quality of human locomotion, the mutual relationships (optimal balance) of these two muscle groups are very important (Hewett, Ford, \& Myer, 2001; Hewett, Myer, \& Zazulak, 2008; Myer, Ford, \& Hewett, 2004). The HQR presents unilateral relation of muscle groups of a single limb. Knee extensors peak torque value should exceed knee flexors peak torque value in 3:2 ratio in favor of quadriceps. Maximum hamstring strength should be at $60 \%$ of maximum quadriceps strength. Many authors provide the value of 0.6 as a normative for $\mathrm{HQR}$ at $60^{\circ} / \mathrm{s}$, which increases up to 0.8 with increased movement velocity (Hewett et al., 2008; Grygorowicz, Kubacki, Pilis, Gieremek, \& Rzepka, 2010; Hadžić, Sattler, Marković, Veselko, \& Dervišević, 2010). HQR is higher at high contraction velocities, which was con-firmed by the results of our study. Values below $60 \%$ are defined as flexor deficit, whereas the values over $68 \%$ are extensor deficit.

Regarding the calculated thigh strength ratios, the observed values for HQR in dominant leg are out the pro-posed normative values for $60 \%$ and they are much more then values observed in other athletes (Cometti, Maffiuletti, Pousson, Chatard, \& Maffulli, 2001; Lehance, Binet, Bury, \& Croisier, 2009; Magalhães, Oliveira, Ascensao, \& Soares, 2004; Zakas, 2006). These data revealed a power deficit of extensors (quadriceps) in our participants. HQR after initial (no stretching) test was 0.84 , hence the knee extensor deficit is present. The HQR ratio reduced to 0.79 after dynamic and after static stretching. It can be concluded that inter-muscular coordination increased after both types of stretching protocols, but not significantly. Based on the relationship between muscle strength and contraction velocity, known as the Hill's curve, it can be concluded that muscle fibers produce more contacts between actin and myosin filament with decreased velocity, i.e. the number of contacts reduce with increased contraction velocity (Maly, Zahalka, \& Mala, 2010). The maximum time available for the contact between actin and myosin filaments re-duces with increasing velocity of concentric activity, as confirmed by the results at $240^{\circ} / \mathrm{s}$ velocity. In case the dy-namic and static stretching protocols are followed by higher muscle contraction velocities $\left(240^{\circ} / \mathrm{s}\right)$, the quadriceps deficit is even bigger. Hamstring, as a weaker muscle group compared to quadriceps, develops into the dominant group at high velocities, so the conclusion here is that forces generated by these two muscle groups equate at high velocities.

So, muscle imbalance is especially pronounced during fast contractions (which dominate in most sports) and increases a risk of non-contact injuries. The ratio between knee extensors and flexors (hamstring to quadriceps strength ratio) is an important factor in the prediction of knee function and injury susceptibility. It is particularly vital when walking, running and jumping, as it controls knee movement during activities that involve speed. When the hamstring strength is within expected values in relation to quadriceps, the result is reduced stress exerted on anterior cruciate ligament (ACL). The anterior cruciate liga- 
ment and hamstring are more susceptible to injuries if there is an imbalance between hamstring and quadriceps (Kim \& Hong, 2011). The stronger the hamstring the better protection for knee during sudden changes in direction and sliding. If the $\mathrm{HQR}$ is low, i.e. imbalanced, the forces of movement in sudden changes of direction are exerted on ACL negatively (overloading it).

Knee extensors are maximally active during landing (deceleration and the control of knee flexion while working eccentrically) and during the take-off phase of the jump, while medium activity is observed during the amortization phase of the jump. Apart from the jumps, the thigh muscles are also strongly involved during the changes of direction that require eccentric leg strength and a short amortization (plyometric) phase, i.e. rapid transition from eccentric to concentric muscle action. Due to these sport-specific demands, top athletes are at the greatest risk of acute ankle sprains and chronic knee conditions. Specifically, patellartendinopathy (jumper's knee) is the single most common overuse sport injury, characterized by pain during tendon loading (Lian, Refsnes, Engebretsen, \& Bahr, 2003; Malliaras, Cook, \& Kent, 2006; Richards, Ajemian, Wiley, Brunet, \& Zernicke, 2002). This finding is not surprising given the above-mentioned strong involvement of thigh muscles in numerous specific activities. Richards et al. (2002) suggested that, among other factors, high rate of knee extensor moment development is also related to patellar tendinopathy.

One of the most important goals of currently used prophylactic training programs is to enhance neuromuscular balance of hamstring and quadriceps muscles (Hewett et al., 2001; Myer et al., 2004). While researchers have re-ported that preventative conditioning program such as plyometrics and balance exercises not only decreased knee injury rates but also improved balance of hamstring and quadriceps (Hewett, Ford, \& Myer, 2006), surprisingly, there is little consensus with regard to whether strength ratio of hamstring to quadriceps can be used as a predictor of noncontact knee or surrounding tissue injuries (Murphy, Connolly, \& Beynnon, 2003).

One explanation of the unclear correlation between $\mathrm{HQR}$ and injuries is that imbalance of strength between hamstrings and quadriceps has been retrospectively associated with the injuries in most of the previous literatures (Willems, 2004). These retrospective studies compared HQR of normal and deficient legs, however, it is unclear if any of the strength imbalance were present before the injury. Therefore, it was suggested that thoroughly designed prospective investigations could clarify the association between HQR and injuries in knee and surrounding tissues (Willems, 2004). While the role of HQR playing in knee and surrounding tissue injuries remain as an enigma, we cannot ignore the current emphasis of prophylactic approach on improving hamstring/quadriceps strength balance.

Although hamstring and quadriceps muscles are directly related to knee joint stabilization, ham-string/quadriceps strength imbalance may not necessarily cause knee injuries. Most of the noncontact athletic lower extremity injuries 
happen during the closed kinetic movement such as running, landing from jumping, pivoting, or crosscutting. It is well known that forces acting upon one joint inevitably affect forces exerting on other linked joints during the closed kinetic movement. The instability at the knee joint can cause dysfunction at ankle, hip, and eventually upper body joints through the kinetic chain because the person would use compensatory movement strategies in order to avoid pain and injuries (Al Awamleh \& Mansi, 2013; Gerdijan, Perić, \& Kazazović, 2017). In this context, it is inferred that even if an athlete with low HQR can successfully avoid knee injury, the strength imbalance still has a considerable potential to impose undesirable stress on ankle or hip joint, which can cause noncontact lower extremity injuries.

\section{Practical Application}

The power output analyzed after the static and dynamic stretching of 10 young healthy males resulted in a positive change for both muscle groups (by power increasing of hamstring and quadriceps). This true for low and high contraction velocities. At the same time, the significant changes for the hamstring to quadriceps strength ratio (HQR) were no found. The data obtained show that acute stretching cannot affect the improvement of the muscle balance between the hamstring and the quadriceps. The optimal HQR can only be achieved by prior long-term systematic treatment (training) of these muscle groups. Ensuing from its accuracy and reliability, isokinetic testing provides precise evaluation and early detection of unilateral and bilateral imbalances. If the values of imbalance in certain muscle groups are high, the likelihood of muscle injuries increases. The isokinetic testing should be a regular procedure in monitoring and the training control.

\section{Conflicts of Interest}

The authors declare no conflicts of interest regarding the publication of this paper.

\section{References}

Al Awamleh, A. A., \& Mansi, T. (2013). Isokinetic Evaluation of Knee Extensor and Flexor Muscles (Quadriceps \& Hamstrings) in-Athletes. Journal of Physical Education and Sport, 13, 601-605.

Behm, D. G., \& Chaouachi, A. (2011). A Review of the Acute Effects of Static and Dynamic Stretching on Performance. European Journal of Applied Physiology, 111, 2633-2651. https://doi.org/10.1007/s00421-011-1879-2

Brandenburg, J. (2006). Duration of Stretch Does Not Influence the Degree of Force Loss Following Static Stretching. Journal of Sports Medicine and Physical Fitness, 46, 526-534.

https://search.proquest.com/openview/6ada4460407e03353f1c83873b4eb04f/1?pq-origs ite $=$ gscholar $\& \mathrm{cbl}=4718$

Christensen, B. K., \& Nordstrom, B. J. (2008). The Effects of Proprioceptive Neuromus- 
cular Facilitation and Dynamic Stretching Techniques on Vertical Jump Performance. Journal of Strength and Conditioning Research, 22, 1826-1831. https://doi.org/10.1007/s00421-011-1879-2

Cohen, J. W. (1988). Statistical Power Analysis for the Behavioral Sciences (2nd Ed.). Hillsdale NJ: Lawrence Erlbaum Associates.

Cometti, G., Maffiuletti, N. A., Pousson, M., Chatard, J. C., \& Maffulli, N. (2001). Isokinetic Strength and Anaerobic Power of Elite, Sub-Elite and Amateur French Soccer Players. International Journal of Sports Medicine, 22, 45-51. https://doi.org/10.1055/s-2001-11331

Dontigny, R. L. (2005). Critical Analysis of the Functional Dynamics of the Sacroiliac Joints as They Pertain to Normal Gait, Journal of Orthopaedic Medicine, 27, 3-10. https://doi.org/10.1080/1355297X.2005.11736245

Fletcher, I. M. (2010). The Effect of Different Dynamic Stretch Velocities on Jump Performance. European Journal of Applied Physiology, 109, 491-498. https://doi.org/10.1007/s00421-010-1386-x

Fletcher, I. M., \& Anness, R. (2007). The Acute Effects of Combined Static and Dynamic Stretch Protocols on Fifty-Meter Sprint Performance in Track-and-Field Athletes. Journal of Strength and Conditioning Research, 21, 784-787. https://doi.org/10.1519/00124278-200708000-00022

Gerdijan, N., Perić, D., \& Kazazović, E. (2017). The Acute Effect of Stretching on Force and Power. Homo Sporticus, 19, 5-11.

https://homosporticus.ba/wp-content/uploads/2019/06/1.-Nikolina-Gerdijan-Du\%C5 \%Alan-Peri\%C4\%87-and-Elvir-Kazazovi\%C4\%87.pdf

Grygorowicz, M., Kubacki, J., Pilis, W., Gieremek, K., \& Rzepka, R. (2010). Selected Isokinetic Test in Knee Injury Prevention. Biology of Sport, 27, 47-51.

Hadžić, V., Sattler, T., Marković, G., Veselko, M., \& Dervišević, E. (2010). The Isokinetic Strength Profile of Quadriceps and Hamstring in Elite Volleyball Players. Isokinetics and Exercise Science, 18, 31-37. https://doi.org/10.3233/IES-2010-0365

Herbert, R. D., \& Gabriel, M. (2002). Effects of Stretching before and after Exercising on Muscle Soreness and Risk of Injury: Systematic Review. British Medical Journal, 325, 468-472. https://doi.org/10.1136/bmj.325.7362.468

Hewett, T. E., Ford, K. R., \& Myer, G. D. (2006). Anterior Cruciate Ligament Injuries in Female Athletes: Part 2, A Meta-Analysis of Neuromuscular Interventions Aimed at Injury Prevention. American Journal of Sports Medicine, 34, 490-498. https://doi.org/10.1177\%2F0363546505282619

Hewett, T. E., Myer, G. D., \& Ford, K. R. (2001). Prevention of Anterior Cruciate Ligament Injuries. Current Women's Health Reports, 1, 218-224.

Hewett, T. E., Myer, G. D., \& Zazulak, B. T. (2008). Hamstring to Quadriceps Peak Torque Ratios Diverge between Sexes with Increasing Isokinetic Angular Velocity. Journal of Science in Medicine Sport, 11, 452-459.

https://doi.org/10.1016/j.jsams.2007.04.009

Holt, B. W., \& Lambourne, K. (2008). The Impact of Different Warm-Up Protocols on Vertical Jump Performance in Male Collegiate Athletes. Journal of Strength and Conditioning Research, 22, 226-229. https://doi.org/10.1519/JSC.0b013e31815f9d6a

Hough, P. A., Ross, E. Z., \& Howatson, G. (2009). Effects of Dynamic and Static Stretching on Vertical Jump Performance and Electromyographic Activity. Journal of Strength and Conditioning Research, 23, 507-512.

https://doi.org/10.1519/JSC.0b013e31818cc65d 
Jaggers, J. R., Swank, A. M., Frost, K. L., \& Lee, C. D. (2008). The Acute Effects of Dynamic and Ballistic Stretching on Vertical Jump Height, Force, and Power. Journal of Strength and Conditioning Research, 22, 1844-1849. https://doi.org/10.1519/JSC.0b013e3181854a3d

Kim, D., \& Hong, J. (2011). Hamstring to Quadriceps Strength Ratio and Noncontact Leg Injuries. A Prospective Study during One Season. Isokinetic Exercise Science, 19, 1-6. https://doi.org/10.3233/IES-2011-0406

Knapik, J., Bullock, S., Canada, S., Toney, E., Wells, J., Hoedebecke, E., \& Jones, B. (2004). Influence of an Injury Reduction Program on Injury and Fitness Outcomes among Soldiers. Injury Prevention, 10, 37-42. http://dx.doi.org/10.1136/ip.2003.002808

Knudson, D., Bennett, K., Corn, R., Leick, D., \& Smith, C. (2001). Acute Effects of Stretching Are Not Evident in the Kinematics of the Vertical Jump. Journal of Strength and Conditioning Research, 15, 98-101. https://doi.org/10.1519/00124278-200102000-00017

Lehance, C., Binet, J., Bury, T., \& Croisier, J. L. (2009). Muscular Strength, Functional Performances and Injury Risk in Professional and Junior Elite Soccer Players. Scandinavian Journal of Medicine and Science in Sports, 19, 243-251. https://doi.org/10.1111/j.1600-0838.2008.00780.x

Lian, O., Refsnes, P. E., Engebretsen, L., \& Bahr, R. (2003). Performance Characteristics of Volleyball Players with Patellar Tendinopathy. American Journal of Sports Medicine, 31, 408-413. https://doi.org/10.1177\%2F03635465030310031401

Little, T., \& Williams, A. G. (2006). Effects of Differential Stretching Protocols during Warm-Ups on High-Speed Motor Capacities in Professional Soccer Players. Journal of Strength and Conditioning Research, 20, 203-207.

Magalhães, J., Oliveira, J., Ascensao, A., \& Soares, J. (2004). Concentric Quadriceps and Hamstrings Isokinetic Strength in Volleyball and Soccer Players. Journal of Sports Medicine and Physical Fitness, 44, 119-125.

https://www.researchgate.net/publication/8246044_Concentric_quadriceps_and_hamst rings_isokinetic_strength_in_volleyball_and_soccer_players

Malliaras, P., Cook, J. L., \& Kent, P. (2006). Reduced Ankle Dorsiflexion Range May Increase the Risk of Patellar Tendon Injury among Volleyball Players. Journal of Science and Medicine in Sport, 9, 304-309. https://doi.org/10.1016/j.jsams.2006.03.015

Maly, T., Zahalka, F., \& Mala, L. (2010). Isokinetic Strength, Ipsilateral and Bilateral Ratio of Peak Muscle Torque in Knee Flexors and Extensors in Elite Young Soccer Players. Acta Kinesiologica, 4, 17-23.

Manoel, M. E., Harris-Love, M. O., Danoff, J. V., \& Miller, T. A. (2008). Acute Effects of Static, Dynamic, and Proprioceptive Neuromuscular Facilitation Stretching on Muscle Power in Women. Journal of Strength and Conditioning Research, 22, 1528-1534. https://doi.org/10.1519/JSC.0b013e31817b0433

Murphy, D. F., Connolly, D. A. J., \& Beynnon, B. D. (2003). Risk Factors for Lower Extremity Injury: A Review of the Literature. British Journal of Sports Medicine, 37, 13-29. http://dx.doi.org/10.1136/bjsm.37.1.13

Myer, G. D., Ford, K. R., \& Hewett, T. E. (2004). Rationale and Clinical Techniques for Anterior Cruciate Ligament Injury Prevention among Female Athletes. Journal of Ath letic Training, 39, 352-364. https://www.researchgate.net/publication/8134811_Rationale_and_Clinical_Technique s_for_Anterior_Cruciate_Ligament_Injury_Prevention_Among_Female_Athletes 
Pearce, A. J., Kidgell, D. J., Zois, J., \& Carlson, J. S. (2009). Effects of Secondary Warm up Following Stretching. European Journal of Applied Physiology, 105, 175-183. https://doi.org/10.1007/s00421-008-0887-3

Pope, R. P., Herbert, R. D., Kirwan, J. D., \& Graham, B. J. (2000). A Randomized Trial of Preexercise Stretching for Prevention of Lower Limb Injury. Medicine and Science in Sports and Exercise, 32, 271-277. https://doi.org/10.1097/00005768-200002000-00004

Power, K., Behm, D., Cahill, F., Carroll, M., \& Young, W. (2004). An Acute Bout of Static Stretching: Effects on Force and Jumping Performance. Medicine and Science in Sports and Exercise, 36, 1389-1396. https://doi.org/10.1249/01.MSS.0000135775.51937.53

Richards, D. P., Ajemian, S. V., Wiley, J. P., Brunet, J. A., \& Zernicke, R. F. (2002). Relation between Ankle Joint Dynamics and Patellar Tendinopathy in Elite Volleyball Players. Clinical Journal of Sport Medicine, 12, 266-272. https://doi.org/10.1097/00042752-200209000-00002

Samuel, M. N., Holcomb, W. R., Guadagnoli, M. A., Rubley, M. D., \& Wallmann, H. (2008). Acute Effects of Static and Ballistic Stretching on Measures of Strength and Power. Journal of Strength and Conditioning Research, 22, 1422-1428. https://doi.org/10.1519/JSC.0b013e318181a314

Small, K., Mc Naughton, L., \& Matthews, M. (2008). A Systematic Review into the Efficacy of Static Stretching as Part of Warm-Up for the Prevention of Exercise-Related Injury. Research in Sports Medicine, 16, 213-231. https://doi.org/10.1080/15438620802310784

Solomonow, M., \& Krogsgaard, M. (2001). Sensorimotor Control of Knee Stability. A Review. Scandinavian Journal of Medicine \& Science in Sports, 11, 64-80. https://doi.org/10.1034/j.1600-0838.2001.011002064.x

Tabachnick, B. G., \& Fidell, L. S. (2013). Using Multivariate Statistics (7th ed.). Boston, MA: Pearson Education.

Taylor, K., Sheppard, J., Lee, H., \& Plummer, N. (2009). Negative Effect of Static Stretching Restored When Combined with a Sport Specific Warm-Up Component. Journal of Science and Medicine in Sport, 12, 657-661. https://doi.org/10.1016/j.jsams.2008.04.004

Torres, E. M., Kraemer, W. J., Vingren, J. L, Volek, J. S., Hatfield, D. L., Spiering, B. A. et al. (2008). Effects of Stretching on Upper Body Muscular Performance. Journal of Strength and Conditioning Research, 22, 1279-1285. https://doi.org/10.1519/JSC.0b013e31816eb501

Unick, J., Kieffer, H., Cheesman, W., \& Feeney, A. (2005). The Acute Effects of Static and Ballistic Stretching on Vertical Jump Performance in Trained Women. Journal of Strength and Conditioning Research, 19, 206-212.

https://doi.org/10.1519/00124278-200502000-00035

Willems, T. (2004). Intrinsic Risk Factors for Sports Injuries to the Lower Leg and Ankle (pp. 33-111). Ghent: Ghent University.

Yamaguchi, T., Ishii, K., Yamanaka, M., \& Yasuda, K. (2008). Acute Effects of Dynamic Stretching Exercise on Power Output during Concentric Dynamic Constant External Resistance Leg Extension. Journal of Strength and Conditioning Research, 21, 1238-1244. https://doi.org/10.1519/00124278-200711000-00044

Young W. B., \& Behm, D. G. (2003). Effects of Running, Static Stretching and Practice Jumps on Explosive Force Production and Jumping Performance. The Journal of Sports Medicine and Physical Fitness, 43, 21-27.

https://www.researchgate.net/publication/10863689_Effects_of_running_static_stretcin 
g_and_practice_jumps_on_explosive_force_production_and_jumping_performance

Young, W. B. (2007). The Use of Static Stretching in Warm-Up for Training and Competition. International Journal of Sports and Physiological Performance, 2, 212-216.

Young, W. B., \& Behm, D. G. (2002). Should Static Stretching be Used during a Warm-Up for Strength and Power Activities? Strength and Conditioning Journal, 24, 33-37. https://doi.org/10.1519/00126548-200212000-00006

Zakas, A. (2006). Bilateral Isokinetic Peak Torque of Quadriceps and Hamstring Muscles in Professional Soccer Players with Dominance on One or Both Two Sides. Journal of Sports Medicine and Physical Fitness, 46, 28-35. 